\title{
Effect of Variable Fluid Properties on Natural Convection of Nanofluids in a Cavity with Linearly Varying Wall Temperature
}

\author{
M. Bhuvaneswari, ${ }^{1}$ Poo Balan Ganesan, ${ }^{1}$ S. Sivasankaran, ${ }^{2}$ and K. K. Viswanathan ${ }^{3}$ \\ ${ }^{1}$ Department of Mechanical Engineering, Faculty of Engineering, University of Malaya, 50601 Kuala Lumpur, Malaysia \\ ${ }^{2}$ Institute of Mathematical Sciences, Faculty of Science, University of Malaya, 50601 Kuala Lumpur, Malaysia \\ ${ }^{3}$ UTM Centre for Industrial and Applied Mathematics, Department of Mathematical Sciences, Universiti Teknologi Malaysia, \\ 81310 Johor Bahru, Johor, Malaysia \\ Correspondence should be addressed to K. K. Viswanathan; visu20@yahoo.com
}

Received 16 October 2014; Revised 24 January 2015; Accepted 25 January 2015

Academic Editor: Quanxin Zhu

Copyright ( $) 2015$ M. Bhuvaneswari et al. This is an open access article distributed under the Creative Commons Attribution License, which permits unrestricted use, distribution, and reproduction in any medium, provided the original work is properly cited.

\begin{abstract}
The present study analyzed convective heat transfer and fluid flow characteristics of nanofluid in a two-dimensional square cavity under different combinations of thermophysical models of nanofluids. The right vertical wall temperature is varying linearly with height and the left wall is maintained at low temperature whereas the horizontal walls are adiabatic. Finite volume method is used to solve the governing equations. Two models are considered to calculate the effective thermal conductivity of the nanofluid and four models are considered to calculate the effective viscosity of the nanofluid. Numerical solutions are carried out for different combinations of effective viscosity and effective thermal conductivity models with different volume fractions of nanoparticles and Rayleigh numbers. It is found that the heat transfer rate increases for Models M1 and M3 on increasing the volume fraction of the nanofluid, whereas heat transfer rate decreases for Model M4 on increasing the volume fraction of the nanoparticle. The difference among the effective dynamic viscosity models of nanofluid plays an important role here such that the average Nusselt number demonstrates an increasing or decreasing trend with the concentration of nanoparticle.
\end{abstract}

\section{Introduction}

Convective heat transfer cooling enhancement technique has been a major problem in engineering and technological applications. In the past, several researchers have conducted research on convective heat transfer technique in various aspects to get better heat transfer medium. Recently, fluids with nanometer sized particles suspended into them called nanofluids are considered in research. Nanofluids are dilute colloidal suspensions containing nanoparticles. The base fluids may be ethylene glycol, refrigerant, water, oil, or mixtures of one or more liquids. The nanoparticles used nanofluids made of metals, metal oxides, carbides, nitride, and carbon. Nanofluids are mainly used as coolant in heat transfer equipment such as heat exchangers, electronic cooling system, and radiators. The novel properties of nanofluids make it potentially useful in many applications, including microelectronics, fuel cells, pharmaceutical processes, hybrid-powered engines, engine cooling, vehicle thermal management, domestic refrigerator, chiller, grinding, machining, and boiler flue gas temperature reduction.

Since detailed investigations in all respects have been required before using the nanofluids in practical applications, we studied theoretically to find the heat transfer and fluid flow characteristics of nanofluid inside a differentially heated cavity under different combinations of thermophysical models of nanofluids in the present study. There are several models used for calculation of physical properties of nanofluid by several researchers [1-3]. Considerable amount of experimental and numerical studies has been conducted for the effect of improvement of the thermal conductivity of nanofluids because most of the researchers are thinking that thermal conductivity plays a dominant role in convective transport [4-6]. However, less number of studies is devoted to the effect of viscosity of the nanofluids. Since the viscosity of the fluid is increased when nanoparticles are suspended into 
them, we must consider the effect of viscosity on convective flow and heat transfer.

Khanafer et al. [7] investigated buoyancy driven convection heat transfer in a two-dimensional enclosure using nanofluids numerically. They found that heat transfer rate increases with an increase in the nanoparticle volume fraction. Hwang et al. [8] theoretically studied the thermal characteristics of natural convection of water based $\mathrm{Al}_{2} \mathrm{O}_{3}$ nanofluids in a rectangular cavity. They showed that the ratio of heat transfer coefficient of nanofluid to that of base fluid is decreased as the size of nanoparticle increases. Ho et al. [9] numerically studied the effects of uncertainties in the effective viscosity and thermal conductivity of nanofluids on convection in enclosure. They concluded that the effective dynamic viscosity should be taken into account when studying the heat transfer efficacy for natural convection in enclosures. Jou and Tzeng [10] performed a numerical study for the effect of small aspect ratio of enclosures on natural convection of nanofluids in a rectangular enclosure. They found that the average Nusselt number at the hot wall is increased as the aspect ratio decreases. Santra et al. [11] studied numerically natural convection of nanofluids in a differentially heated square cavity. They treated the nanofluid as non-Newtonian. Sivasankaran et al. [12] numerically studied the free convection of nanofluids with different nanoparticles in a square cavity with linearly varying wall temperature. They found that the increment in average Nusselt number strongly depends on the nanoparticle chosen. Rashmi et al. [13] numerically studied natural convection of nanofluids using computational fluid dynamics approach. They found that heat transfer decreases on increasing the particle volume fraction. Sivasankaran and Pan [14] numerically investigated natural convection of nanofluids in a cavity with sinusoidal temperature distributions on vertical sidewalls. It is observed that the heat transfer rate is enhanced by nonuniform temperature distributions of both walls as compared to the case of uniform heating on one wall. Cianfrini et al. [15] numerically studied the free convection of nanofluids in a partially heated cavity. They found that the heat transfer decreases as the nanoparticle size, the width of the cavity, and the length of the heater are increased. Bouhalleb and Abbassi [16] numerically examined the natural convection of nanofluid in an inclined rectangular cavity heated from one side and cooled from the ceiling. They observed that heat transfer increases first and then decreases on increasing the inclination of the enclosure for all aspect ratios.

In addition, most of the previous studies investigate the convection heat transfer with either uniform wall temperature or uniform heat flux thermal boundary conditions. However, these thermal boundary conditions are not suitable in many practical applications such as heat exchangers, injection moldings, and solidification processes. The effect of temperature dependent properties of water near its density maximum on convection is studied numerically by Sivasankaran and Ho [17]. They found that the temperature difference parameter did not create any significant effect on the heat transfer. Sivasankaran et al. [18] analyzed the magnetoconvection of cold water in an open cavity with temperature dependent properties. They found that the Nusselt number behaves nonlinearly with Marangoni number.

In most of the numerical or experimental studies on convection heat transfer of nanofluids, researchers have considered the effect of physical properties; particularly, the thermal conductivity of nanofluids on natural convection in enclosures and very few investigations for viscosity are found in the literature. There are many models for thermophysical properties of nanofluids based on experimental data or theoretical results available in the literature. In most of the studies on convection heat transfer in cavities, researchers take any one of the models and investigate the heat transfer and fluid flow characteristics inside the cavity. Very few studies only concentrate on comparing the models of thermophysical properties of nanofluid.

Also, we need the knowledge of the effect of variable wall temperature on some applications. Therefore, the present study aims to investigate the effect of different models of effective viscosity and thermal conductivity of $\mathrm{Al}_{2} \mathrm{O}_{3}$ nanofluid on natural convection in a cavity with linearly varying wall temperature.

\section{Mathematical Analysis}

Consider a two-dimensional square cavity of length $L$ filled with nanofluids as shown in Figure 1 . The cavity is heated differentially between the two vertical sidewalls at different temperature. The left wall temperature is varying linearly with height. The horizontal walls are assumed to be adiabatic, nonconducting, and impermeable to mass transfer. The nanofluid in the enclosure is a solid-liquid mixture with uniform volume fraction $\phi$, shape, and size of nanoparticles $\left(\mathrm{Al}_{2} \mathrm{O}_{3}\right)$ dispersed within base fluid water and it is also Newtonian. The flow is assumed to be incompressible and laminar. It is assumed that both nanoparticles and base fluid are in thermal equilibrium. The Boussinesq approximation is valid in the buoyancy term and all other thermophysical properties are assumed to be constant. In addition, the viscous dissipation is assumed to be negligible.

The mathematical model for fluid flow and heat transfer for the above said geometrical conditions and assumptions presented in nondimensional form are as follows.

\section{Momentum Equation. Consider}

$$
\begin{gathered}
\frac{\partial U}{\partial F_{o}}+U \frac{\partial U}{\partial X}+V \frac{\partial U}{\partial Y} \\
=-\frac{\partial P}{\partial X}+\frac{C_{p, b f}^{*}}{k_{b f}^{*}}\left[\frac{\partial}{\partial X}\left(2 \mu_{b f}^{*} \frac{\partial U}{\partial X}\right)+\frac{\partial}{\partial Y}\left(\mu_{b f}^{*} \frac{\partial U}{\partial Y}\right)\right. \\
\left.+\frac{\partial \mu_{b f}^{*}}{\partial Y} \frac{\partial V}{\partial X}+\mu_{b f}^{*} \frac{\partial^{2} V}{\partial X \partial Y}\right] \\
+\operatorname{Ra}_{T, f} \operatorname{Pr}_{f} \beta_{T, b f}^{*}\left(\frac{\rho_{p b}^{*} C_{p, b f}^{*}}{k_{b f}^{*}}\right)^{2} \theta
\end{gathered}
$$




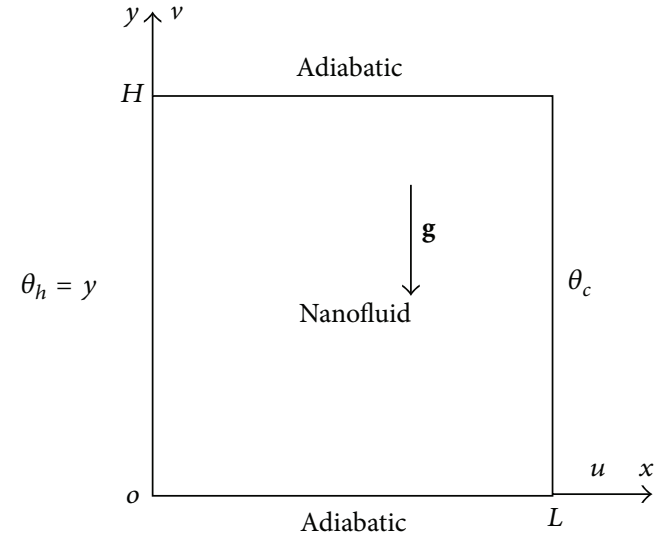

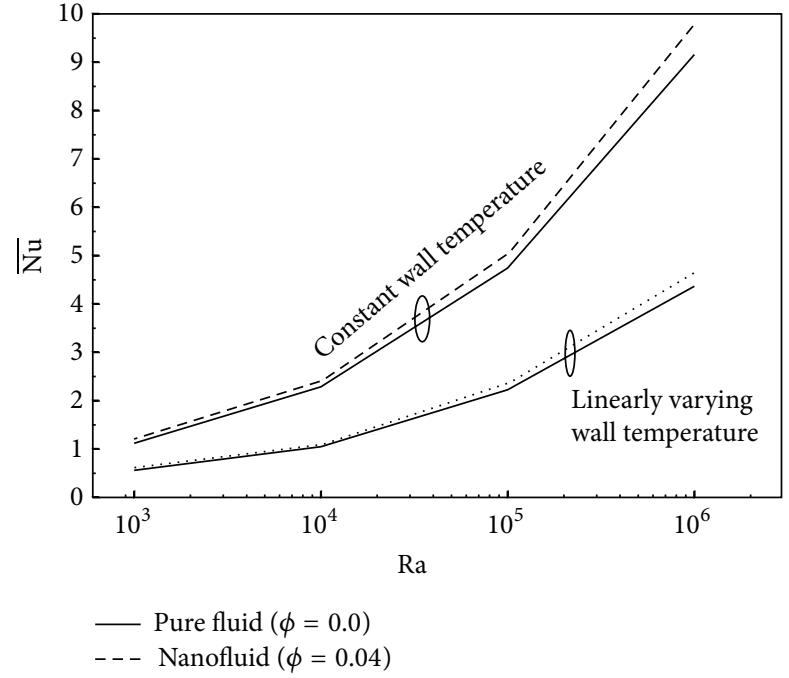

(b)

Figure 1: (a) Physical configuration and coordinate systems. (b) Comparison of average Nusselt number for isothermal and linearly varying wall temperatures of pure fluid and nanofluid with $\phi=0.04$.

$$
\begin{gathered}
\frac{\partial V}{\partial F_{o}}+V \frac{\partial V}{\partial X}+V \frac{\partial V}{\partial Y} \\
=-\frac{\partial P}{\partial Y}+\frac{C_{p, b f}^{*}}{k_{b f}^{*}}\left[\frac{\partial}{\partial X}\left(2 \mu_{b f}^{*} \frac{\partial V}{\partial X}\right)+\frac{\partial}{\partial Y}\left(\mu_{b f}^{*} \frac{\partial V}{\partial Y}\right)\right. \\
\left.+\frac{\partial \mu_{b f}^{*}}{\partial Y} \frac{\partial U}{\partial X}+\mu_{b f}^{*} \frac{\partial^{2} U}{\partial X \partial Y}\right] .
\end{gathered}
$$

\section{Energy Equation. Consider}

$$
\frac{\partial T}{\partial F_{o}}+U \frac{\partial T}{\partial X}+V \frac{\partial T}{\partial Y}=\left[\frac{\partial}{\partial X}\left(k_{e n}^{*} \frac{\partial T}{\partial X}\right)+\frac{\partial}{\partial Y}\left(k_{e n}^{*} \frac{\partial T}{\partial Y}\right)\right]
$$

The physical properties' ratios presented in (1) and (3) are as follows: $k_{n f}^{*}=k_{n} / k_{f}, k_{e n}^{*}=k_{e} / k_{n}, \mu_{n f}^{*}=\mu_{n} / \mu_{f}, c_{p, n f}^{*}=$ $c_{p, n} / c_{p, f}, \rho_{n f}^{*}=\rho_{n} / \rho_{f}$, and $\beta_{n f}^{*}=\beta_{n} / \beta_{f}$, where the subscripts $n$ and $f$ denote, respectively, the nanofluid and the base fluid. Moreover, $k_{e}$ denotes the effective thermal conductivity associated with the possible heat transfer enhancement mechanisms of the nanofluid such as Brownian motion, liquid layering at liquid/particle interface, and phonon movement in nanoparticles.

The effective thermophysical properties of the nanofluid can be evaluated using various formulae available in the literature. In the present study, the focus is on the effects of the effective viscosity and thermal conductivity of the nanofluid on natural convection heat transfer. The formulae selected for the thermophysical properties of the nanofluid in the present model are as follows.

Density. Consider

$$
\rho_{n}=(1-\phi) \rho_{f}+\phi \rho_{p}
$$

Thermal Expansion Coefficient. Consider

$$
\beta_{n}=\frac{1}{\rho_{n}}(1-\phi) \rho_{f} \beta_{f}+\phi \rho_{p} \beta_{p}
$$

Specific Heat. Consider

$$
c_{p, n}=(1-\phi) c_{p, f}+\phi c_{p, p}
$$

Thermal Conductivity. Thermal conductivity is evaluated from the well-known Maxwell formula [8] as

$$
k_{n}=k_{f}\left[\frac{2+k_{p f}^{*}+2 \phi\left(k_{p f}^{*}-1\right)}{2+k_{p f}^{*}-\phi\left(k_{p f}^{*}-1\right)}\right] \quad(\text { Case A) }
$$

with $k_{p f}^{*}=k_{p} / k_{f}$ and Pak and Cho's correlation [1] as

$$
k=k_{f}(1+7.47 \phi) \quad(\text { Case } \mathrm{B}) .
$$

Dynamic Viscosity. For the effective dynamic viscosity of nanofluid, Brinkman's formula [19], an empirical correlation obtained by Maiga et al. [20], Brownian motion model [9], 


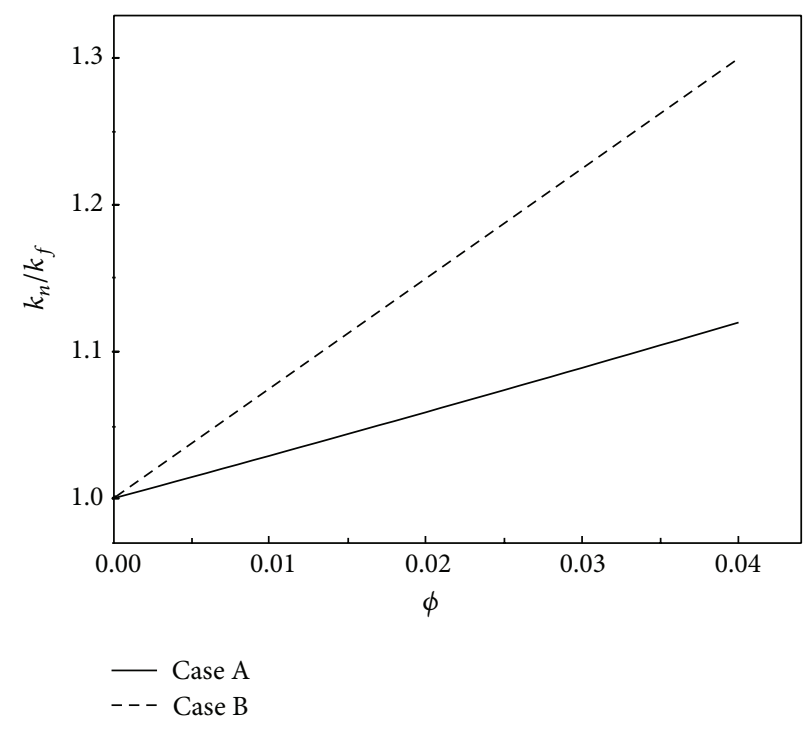

(a)

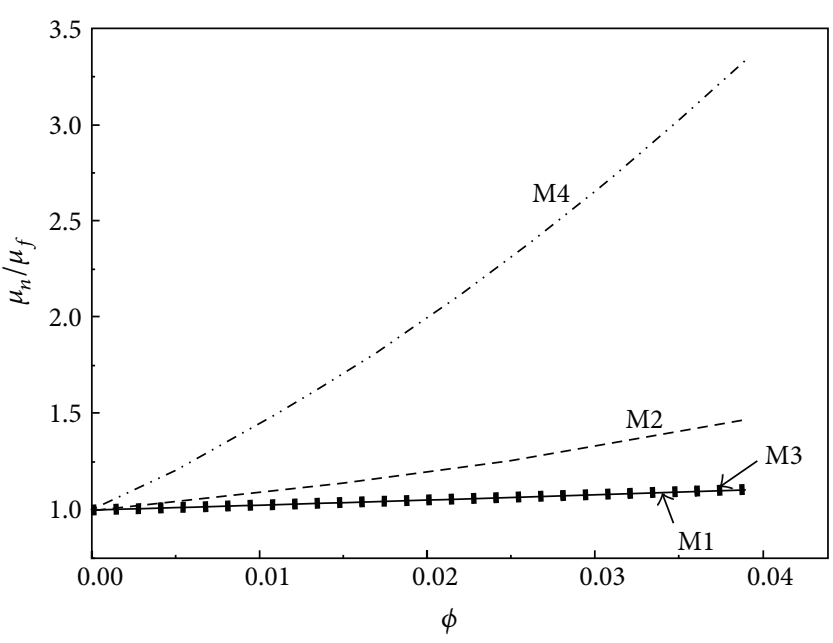

(b)

FIGURE 2: (a) Comparison of two models adopted for thermal conductivity enhancement. (b) Comparison of four models adopted for viscosity enhancement.

and Pak and Cho's correlation [1] are considered here. They are expressed as

$$
\begin{aligned}
& \mu_{n}=\mu_{f}(1-\phi)^{-2.5} \quad(\text { Model M1 }) \\
& \mu_{n}=\mu_{f}\left(1+7.3 \phi+123 \phi^{2}\right) \quad(\text { Model M2) } \\
& \mu_{n}=\mu_{f}\left(1+2.5 \phi+6.17 \phi^{2}\right) \quad(\text { Model M3) } \\
& \mu_{n}=\mu_{f}\left(1+39.11 \phi+533.9 \phi^{2}\right) \quad \text { (Model M4). }
\end{aligned}
$$

The above four equations ((9)-(12)) are referred to as Model M1-Model M4 in this study, respectively. The thermophysical properties of the base fluid (water) and nanoparticles $\left(\mathrm{Al}_{2} \mathrm{O}_{3}\right)$ are available in the literature [9].

The stream function is calculated using $U=\partial \Psi / \partial Y$ and $V=-\partial \Psi / \partial X$. No slip boundary conditions are applied on all four walls of the cavity. The initial and boundary conditions on these equations specified in the dimensionless form are

$$
\begin{gathered}
F_{o}=0 ; \quad U=V=T=0, \\
\text { at } 0 \leq X \leq 1, \quad 0 \leq Y \leq 1 \\
F_{o}>0 ; \quad U=V=\frac{\partial T}{\partial X}=0, \quad \text { at } Y=0 \& 1, \\
U=V=0, \quad T=Y, \quad \text { at } X=0, \\
U=V=0, \quad T=0, \quad \text { at } X=1 .
\end{gathered}
$$

The following nondimensional variables are used: $(X, Y)=(x, y) / L,(U, V)=(u, v) L / \alpha_{n}, F_{o}=t \alpha_{n} / L^{2}$, $P=p L^{2} /\left(\rho_{n} \alpha_{n}^{2}\right)$, and $T=\left(\theta-\theta_{c}\right) /\left(\theta_{h}-\theta_{c}\right)$. The heat transfer rate at the hot wall of the enclosure is presented by means of the Nusselt number, which is evaluated as follows:

$$
\mathrm{Nu}_{h}=\frac{h_{n} L}{k_{f}}=-\left.k_{n f}^{*} \frac{\partial T}{\partial Y}\right|_{X=0}
$$

resulting in the average Nusselt number as

$$
\overline{\mathrm{Nu}}=\int_{0}^{1} \mathrm{Nu}_{h} d Y
$$

Furthermore, to quantify heat transfer efficacy of using nanofluid, a ratio of the averaged heat transfer coefficient at the hot wall to that of the base fluid is evaluated as $\varepsilon_{h}=\overline{h_{n}} / \overline{h_{f}}$.

\section{Method of Solution}

The nondimensional equations subject to the boundary conditions are solved by control volume method. The QUICK scheme is used for the convection terms and central difference scheme is used for diffusion terms. The solution domain consists of a number of grid points at which discretization equations are applied. The nonuniform grid has been selected in both $X$ and $Y$ directions. The grid sizes were tested from $41 \times 41$ to $161 \times 161$ for $\mathrm{Ra}=10^{6}, \mathrm{Pr}=6.7$, and constant fluid properties. It is observed from the grid independence test that an $81 \times 81$ grid is enough to investigate the problem. The resulting algebraic equations are solved by iterative method. The convergence criterion used for the field variables $\phi(=$ $T, U, V)$ is $\left|\left(\phi_{i, j}^{n+1}-\phi_{i, j}^{n}\right) / \phi_{i, j}^{n+1}\right| \leq 10^{-6}$.

\section{Results and Discussions}

Numerical study is performed to understand the natural convective flow and heat transfer characteristics of nanofluid 

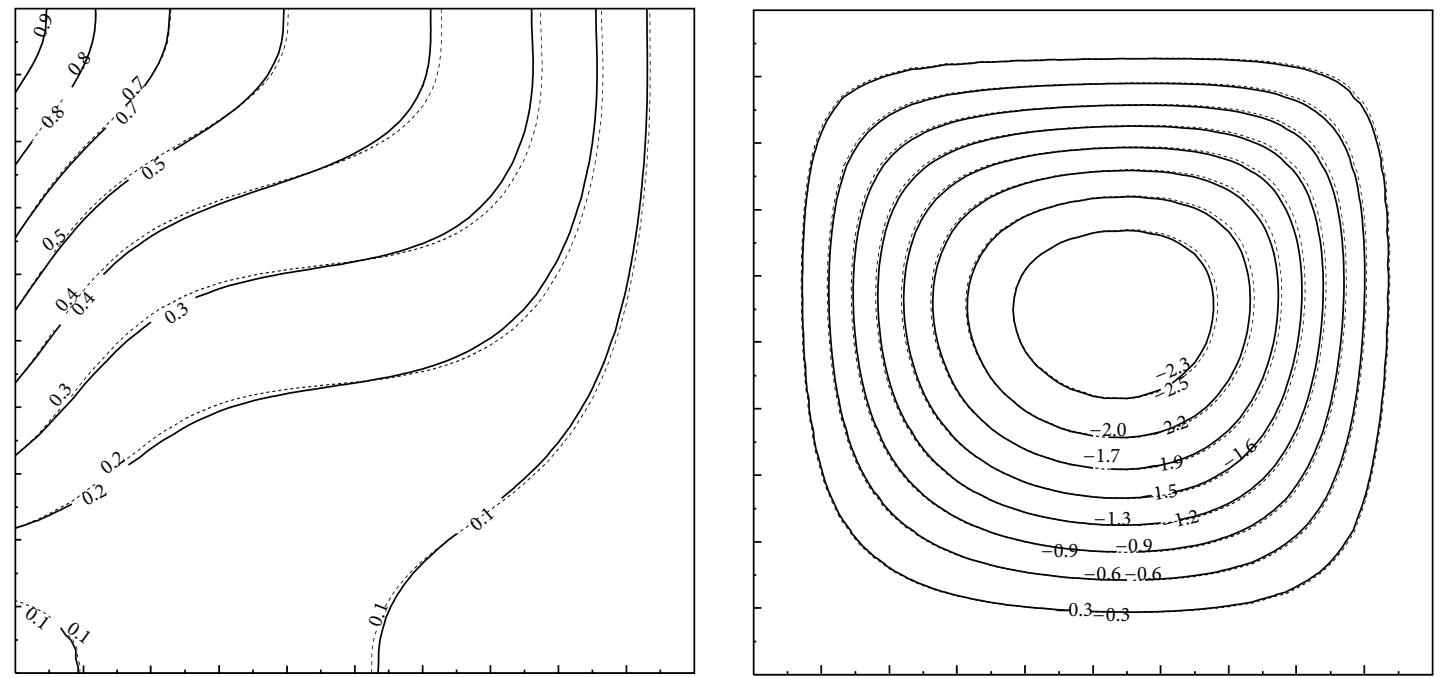

(a) Model M1
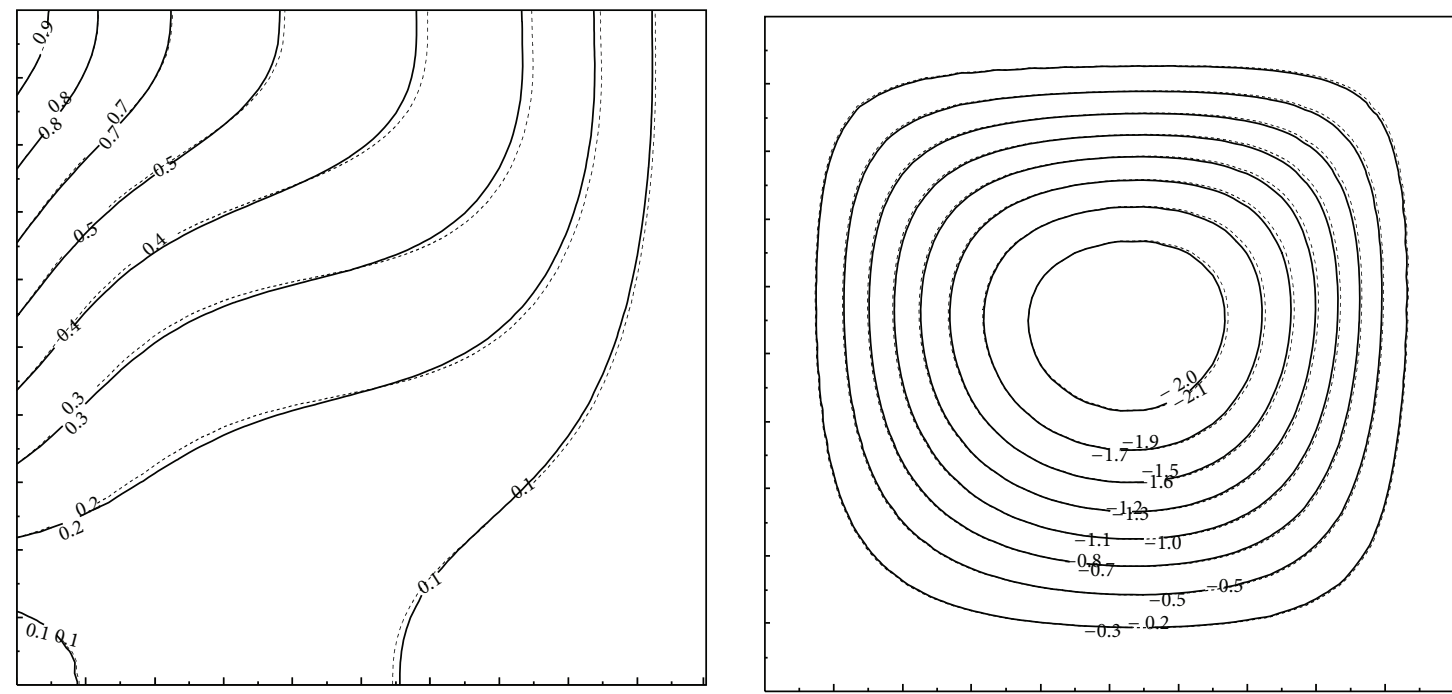

(b) Model M2
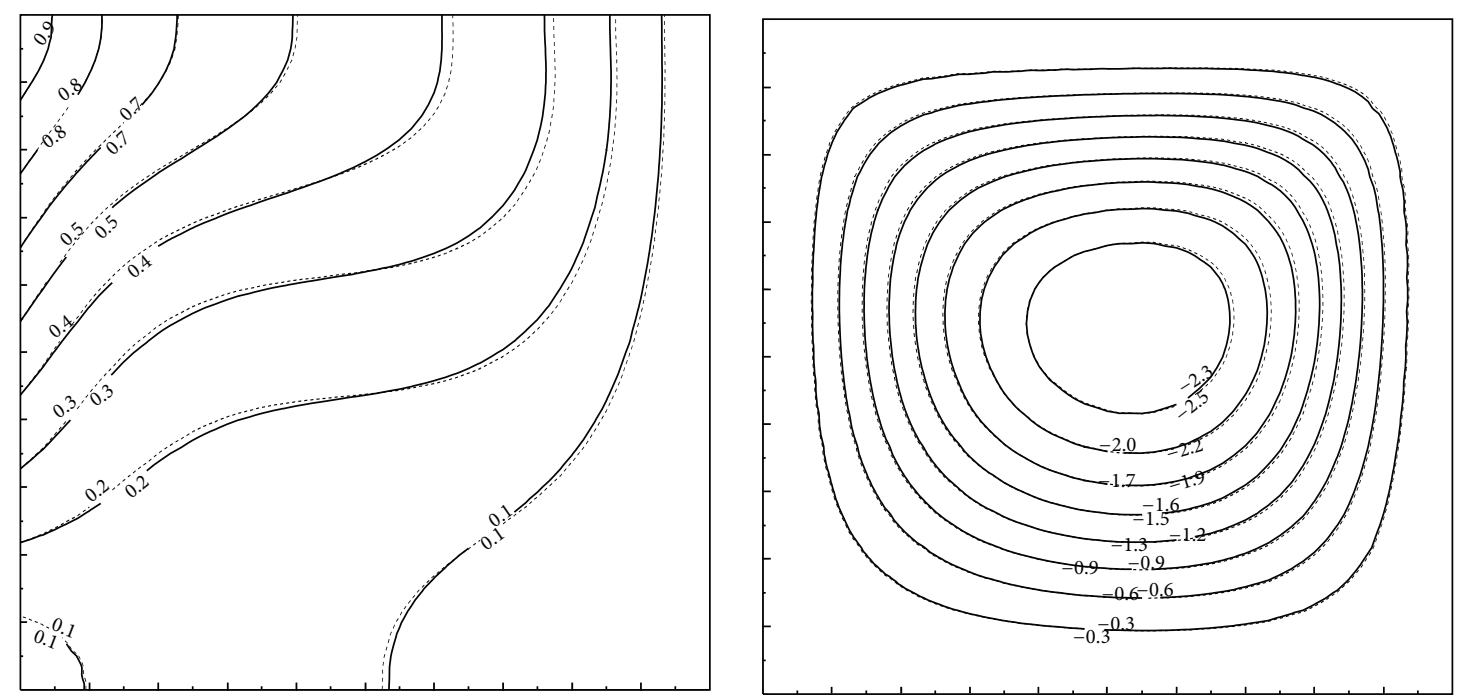

(c) Model M3

Figure 3: Continued. 

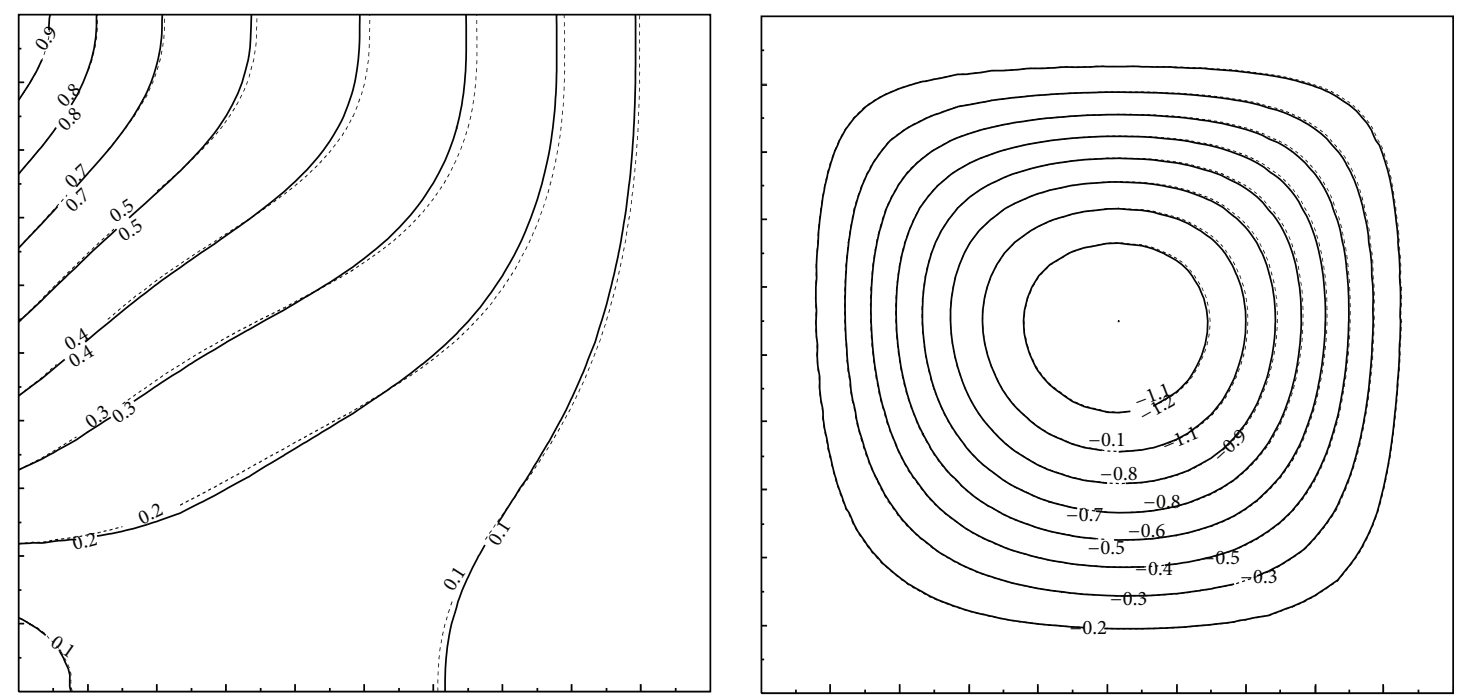

(d) Model M4

FIgURE 3: Isotherms and streamlines for different models with $\mathrm{Ra}=10^{4}$ and $\phi=0.04$. (Dashed line: Case A; solid line: Case B).

with two effective thermal conductivity and four effective viscosity models for different volume fractions of nanoparticles in a square cavity. The value of Prandtl number is taken to be 6.7. Computations are carried out for Rayleigh number ranging from $10^{3}$ to $10^{6}$ and for the volume fraction $\phi$ of nanoparticles from $0 \%$ to $4 \%$. Results for both cases of effective thermal conductivity and four models of effective viscosity of the nanofluid are discussed under different combinations of parameters involved in the study. Figure 1(b) shows the comparison of average Nusselt number between isothermal and linearly varying hot wall temperatures on pure fluid and nanofluid with the volume fraction $\phi=0.04$. It is clearly seen from the figure that linearly varying wall temperature gives lower heat transfer rate than the isothermal wall and the difference increases on increasing the Rayleigh number.

Figure 2(a) shows the comparison of two thermal conductivity models defined in (7) and (8). It is clearly seen that the well-known theoretical Maxwell model gives higher thermal conductivity than the Pak and Cho correlation based on experimental data. The effect of these two models on heat transfer and fluid flow characteristics inside the cavity is analyzed in the present study. The effective viscosity of various models adopted in this study is shown in Figure 2(b). Among these four equations, Pak and Cho's correlation gives more viscosity than the other three models. The Brinkman formula and correlation by Maiga et al. furnish similar trend with increasing the particle volume concentration of nanofluid and give low viscosity among the models. Figures 3(a)-3(d) show the heat transfer and fluid flow characteristics of different models of viscosity and thermal conductivity of nanofluid with $\mathrm{Ra}=10^{4}$ and $\phi=0.04$. There is no much difference in temperature distributions and flow pattern observed among the four models of viscosity and very slight variation is found between two cases of thermal conductivity. Since the buoyancy force is weak, the isotherms are equally distributed inside the cavity and single cell flow pattern occupied the whole cavity. Figures 4(a)-4(d) display the isotherms and streamlines for different models of viscosity and two cases of effective thermal conductivity of nanofluid with $\mathrm{Ra}=10^{6}$ and $\phi=0.04$. The same behaviour found in the case of $\mathrm{Ra}=10^{4}$ is observed among the various models of viscosity and thermal conductivity of nanofluid. For high values of Rayleigh number, the isotherms are clustered near the walls of the cavity and boundary layer type flow is formed, which reflects high energy transport across the cavity. Isotherms also indicate the horizontal temperature stratification. It is observed from Figures 3 and 4 that there is no much difference in fluid flow and heat distributions among the various models of viscosity and thermal conductivity of nanofluid of $4 \%$ volume concentration.

In order to find the effect of heat transfer rate across the cavity for different models at various particle concentrations of nanofluid, the average Nusselt number is plotted against Rayleigh number for various models of viscosity and thermal conductivity in Figures 5(a)-5(d). It is found that heat transfer rate increases on increasing the value of Rayleigh number for all models of viscosity and two cases of thermal conductivity of nanofluid. When increasing the particle concentration, heat transfer rate increases or decreases depending on the model considered.

Model M1 provides heat transfer enhancement with increasing particle concentration of nanofluid for two cases of thermal conductivity. A further scrutiny of the curves in Figure 5(a) reveals that heat transfer rate is slightly higher for Case B than that for Case A. This is because Case B is having higher values of effective thermal conductivity than Case A, which is shown in Figure 2(a). Model M2 gives contradictory results between Case A and Case B, that is, the two adopted formulas for effective thermal conductivity of nanofluid. In Case $\mathrm{A}$, heat transfer rate decreases on increasing the volume concentration of nanofluid. But in 

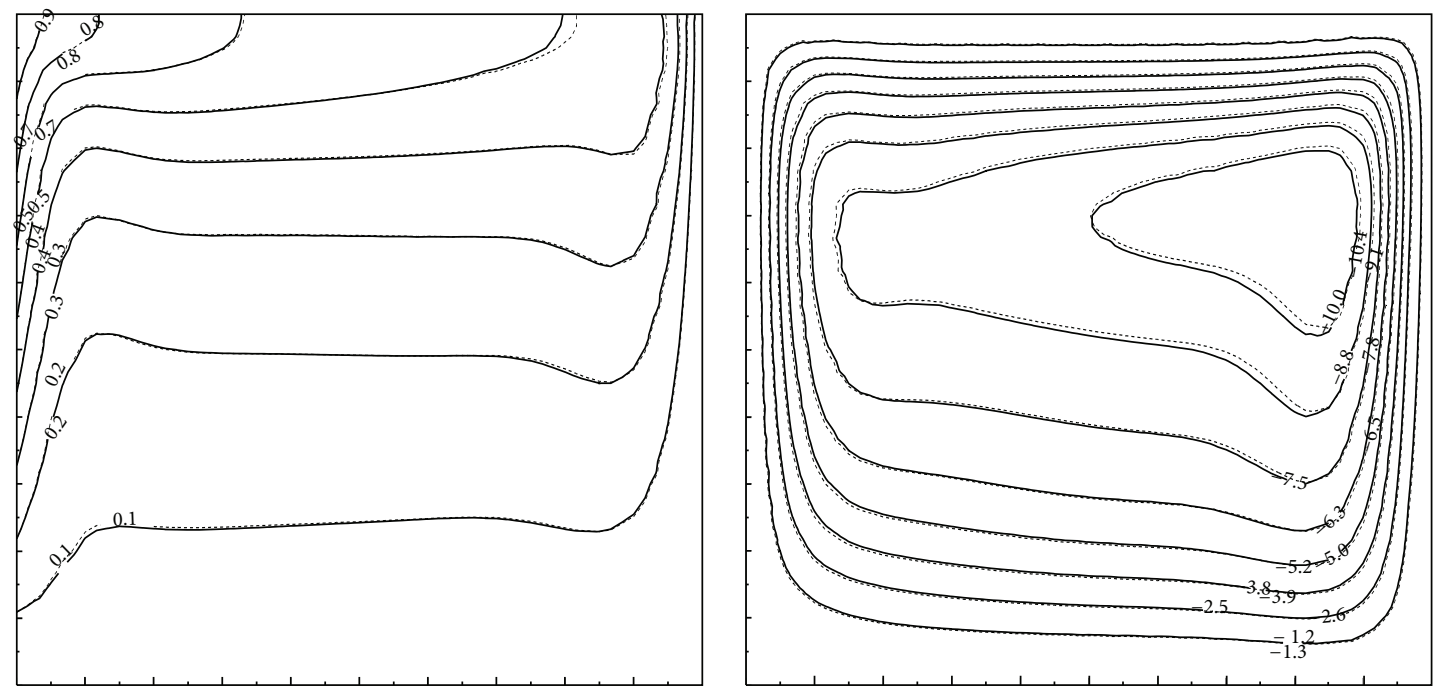

(a) Model M1
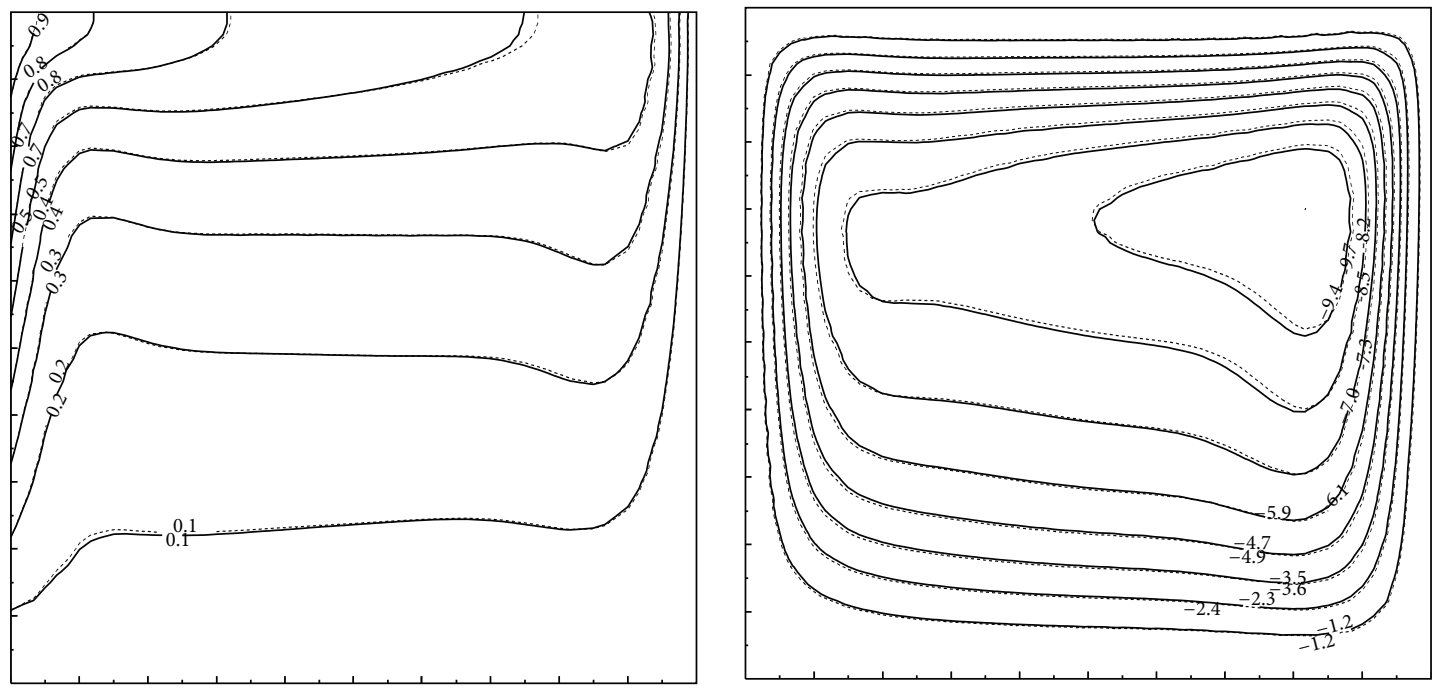

(b) Model M2
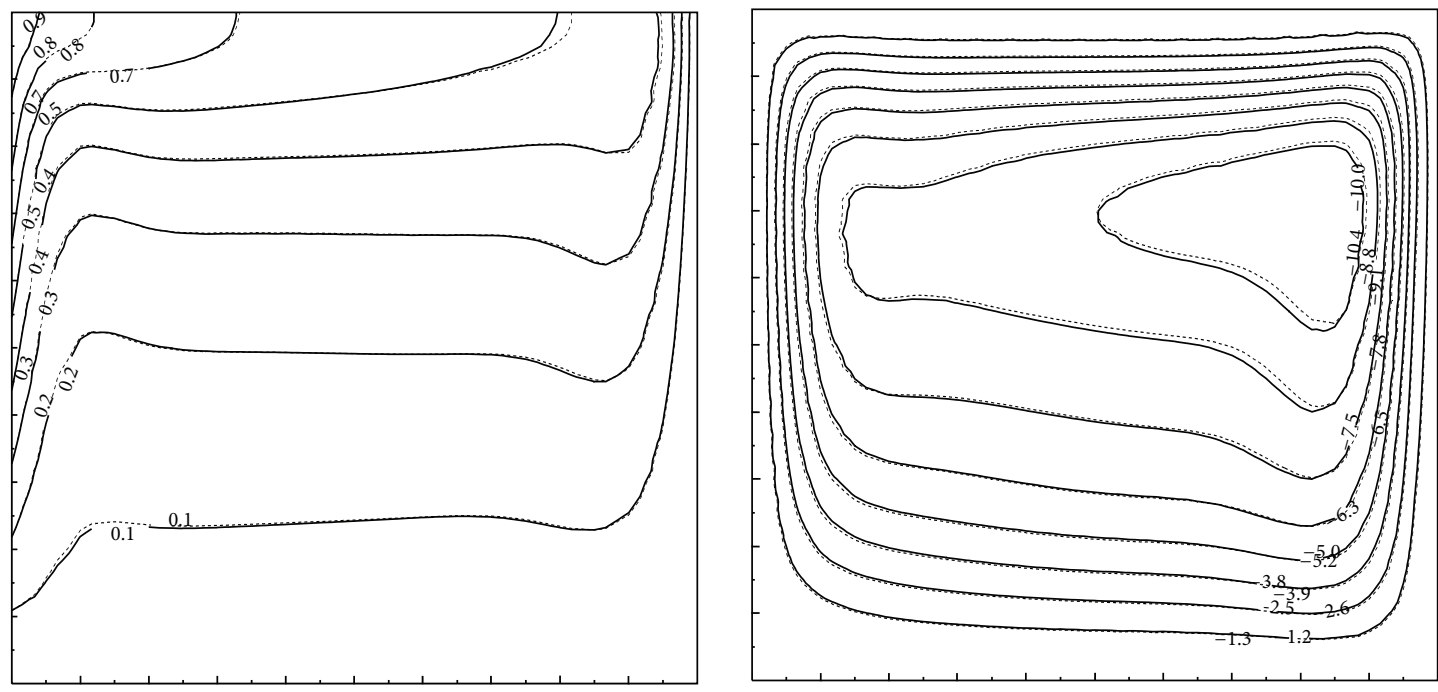

(c) Model M3

FIgURE 4: Continued. 

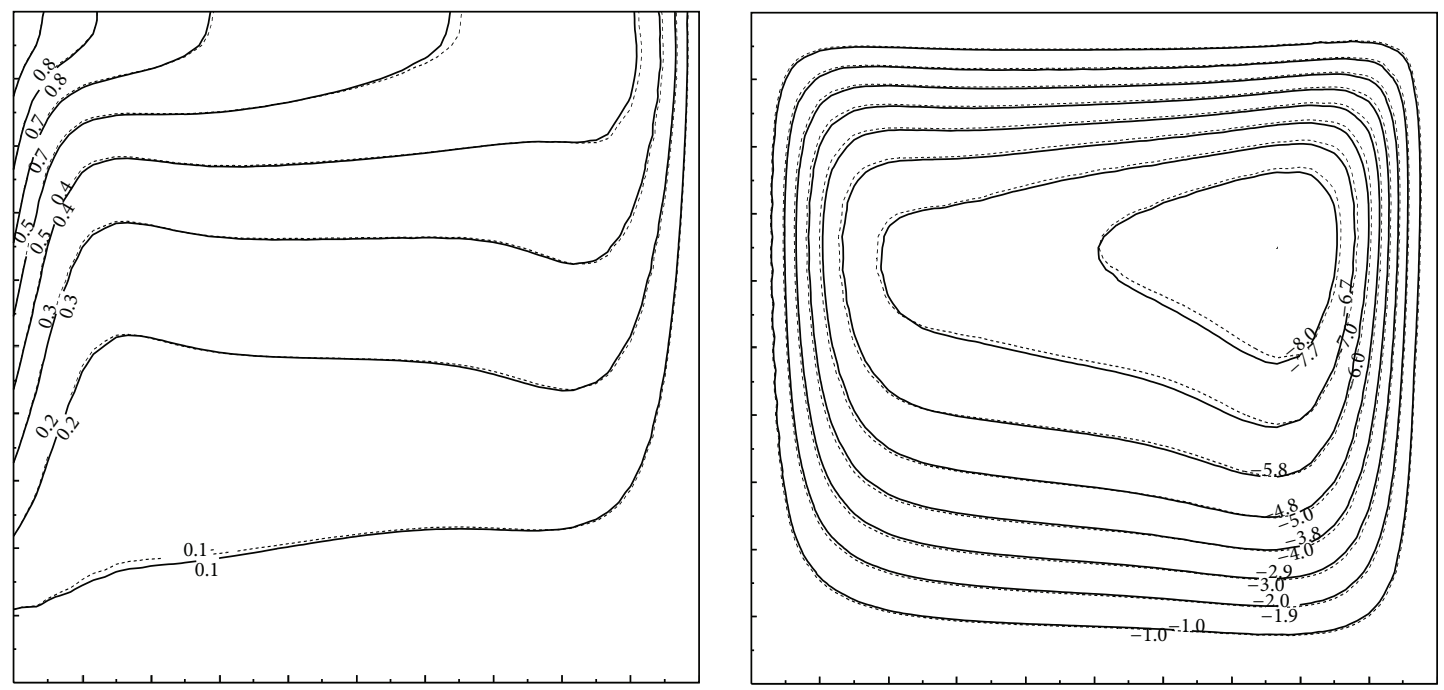

(d) Model M4

FIgURE 4: Isotherms and streamlines for different models with $\mathrm{Ra}=10^{6}$ and $\phi=0.04$. (Dashed line: Case A; solid line: Case B).

Case $\mathrm{B}$, heat transfer rate increases on increasing the volume concentration. Though the viscosity of model M2 is low compared to other models adopted here, heat transfer rate is not enhanced for $\mathrm{Ra} \geq 10^{4}$. For weak buoyancy force, heat transfer is dominated by conduction mode. Average Nusselt number against Rayleigh number of Model M3 is depicted in Figure 5(c) for two cases of effective thermal conductivity. A similar trend as that in Figure 5(a) is observed for Model M3 also. That is, heat transfer rate increases with concentration of nanoparticle for all values of Rayleigh number. Figure 5(d) shows the average Nusselt number of Model M4 for two cases of effective thermal conductivity of nanofluid. When increasing the volume concentration of particles, heat transfer rate decreases for all values of Rayleigh number in Case A. However, heat transfer rate enhances for $\mathrm{Ra}=10^{3}$ in Case $\mathrm{B}$ and it decreases for all other values of Rayleigh number in Case B. Since the effective thermal conductivity is very high, we get an enhancement in heat transfer in this case.

The difference among the effective dynamic viscosity of nanofluid using four different models comes into playing an important role here such that the average Nusselt number curves shown in Figure 5 exhibit an increasing or decreasing trend with concentration of nanoparticle. Some models used in the study did not provide an enhancement in heat transfer rate, which is contradiction to the results of published work [8] in the literature regarding heat transfer efficacy of using nanofluid for natural convection in enclosures. To find the heat transfer efficacy of the nanofluid, heat transfer coefficient ratio $\left(\varepsilon_{h}\right)$ is plotted against Rayleigh number for different volume fractions of nanoparticles with various models in Figures 6(a)-6(d). Models M1 and M3 provide heat transfer enhancement for all values of Rayleigh number and two cases of thermal conductivity. Heat transfer coefficient ratio $\varepsilon_{h}$ is always above the unity for Models M1 and M3, which is clearly seen in Figures 6(a) and 6(c). In Model M2, heat transfer coefficient ratio $\varepsilon_{h}$ is above unity for Case $\mathrm{B}$ and below the unity except $\mathrm{Ra}=10^{3}$ for Case A; see Figure 6(b). The heat transfer coefficient ratio for a fixed volume concentration of nanoparticle drops drastically at $\mathrm{Ra}=10^{4}$ in all models and it increases after that; that is, $\mathrm{Ra}>10^{4}$.

Considering Case A, that is, Maxwell formula for effective thermal conductivity of nanofluid, viscosity Models M1 and M3 provide enhancement on heat transfer rate for all values of Rayleigh number. Models M2 and M4 provide enhancement on heat transfer rate for low values of Rayleigh number and decrease the heat transfer rate for $\mathrm{Ra} \geq 10^{4}$. The average Nusselt number of nanofluid with $4 \%$ volume concentration for Model M1 increases by $6.4 \%$ and $9.7 \%$ for $\mathrm{Ra}=10^{6}$ and $\mathrm{Ra}=10^{3}$, respectively, compared to that of base fluid. Heat transfer rate of nanofluid with $4 \%$ volume concentration for Model M2 of Case A decreases by $2.1 \%$ and increases by $6.9 \%$ for $\mathrm{Ra}=10^{6}$ and $\mathrm{Ra}=10^{3}$, respectively, compared to that of base fluid. Model M3 for nanofluid with $4 \%$ volume concentration provides an enhancement on heat transfer rate of about $6.3 \%$ and $9.6 \%$ for $\mathrm{Ra}=10^{6}$ and $\mathrm{Ra}=$ $10^{3}$, respectively, compared to that of base fluid. In Case $\mathrm{B}$, that is, Pak and Cho's correlation for effective thermal conductivity of nanofluid, viscosity Models M1, M2, and M3 provide enhancement on heat transfer rate for all values of Rayleigh number and Model M4 provides enhancement on heat transfer rate for low values of Rayleigh number and decreases the heat transfer rate for $\mathrm{Ra} \geq 10^{4}$. The average Nusselt number of nanofluid with $4 \%$ volume concentration for Models M1, M2, and M3 increases by $18.35 \%, 8.85 \%$, and $18.28 \%$ for $\mathrm{Ra}=10^{6}$ and increases by $25.4 \%, 22.6 \%$, and $25.4 \%$ for $\mathrm{Ra}=10^{3}$, respectively, compared to that of base fluid. Heat transfer rate of nanofluid with $4 \%$ volume concentration for Model M4 decreases by $14.5 \%$ and increases by $18.6 \%$ for $\mathrm{Ra}=10^{6}$ and $\mathrm{Ra}=10^{3}$, respectively, compared to that of base fluid. 

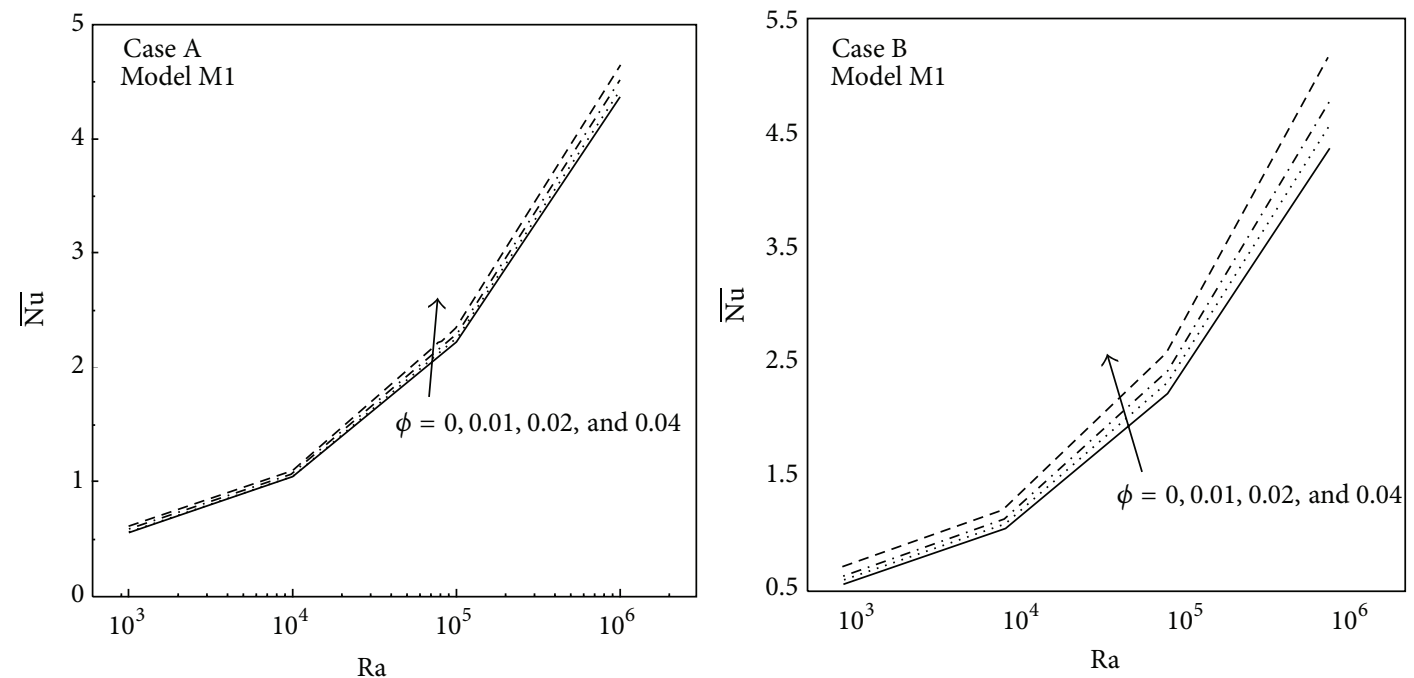

(a) Model M1
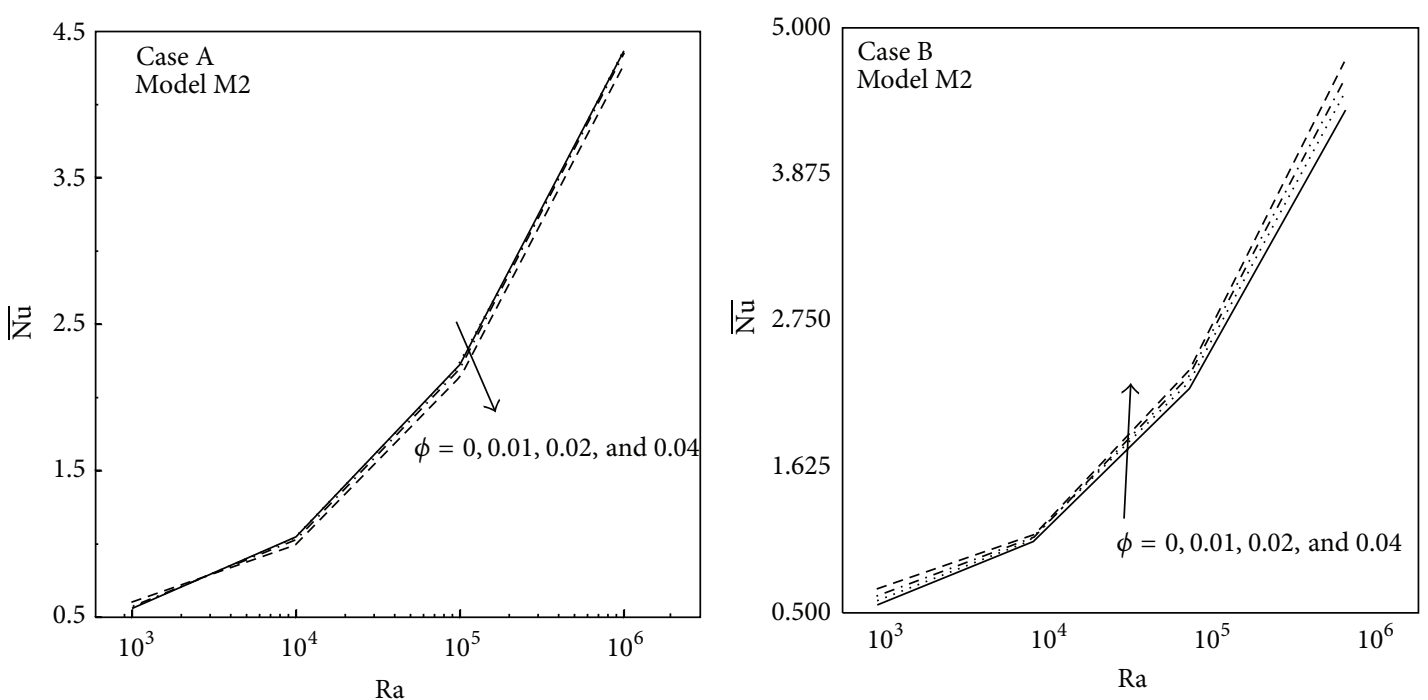

(b) Model M2
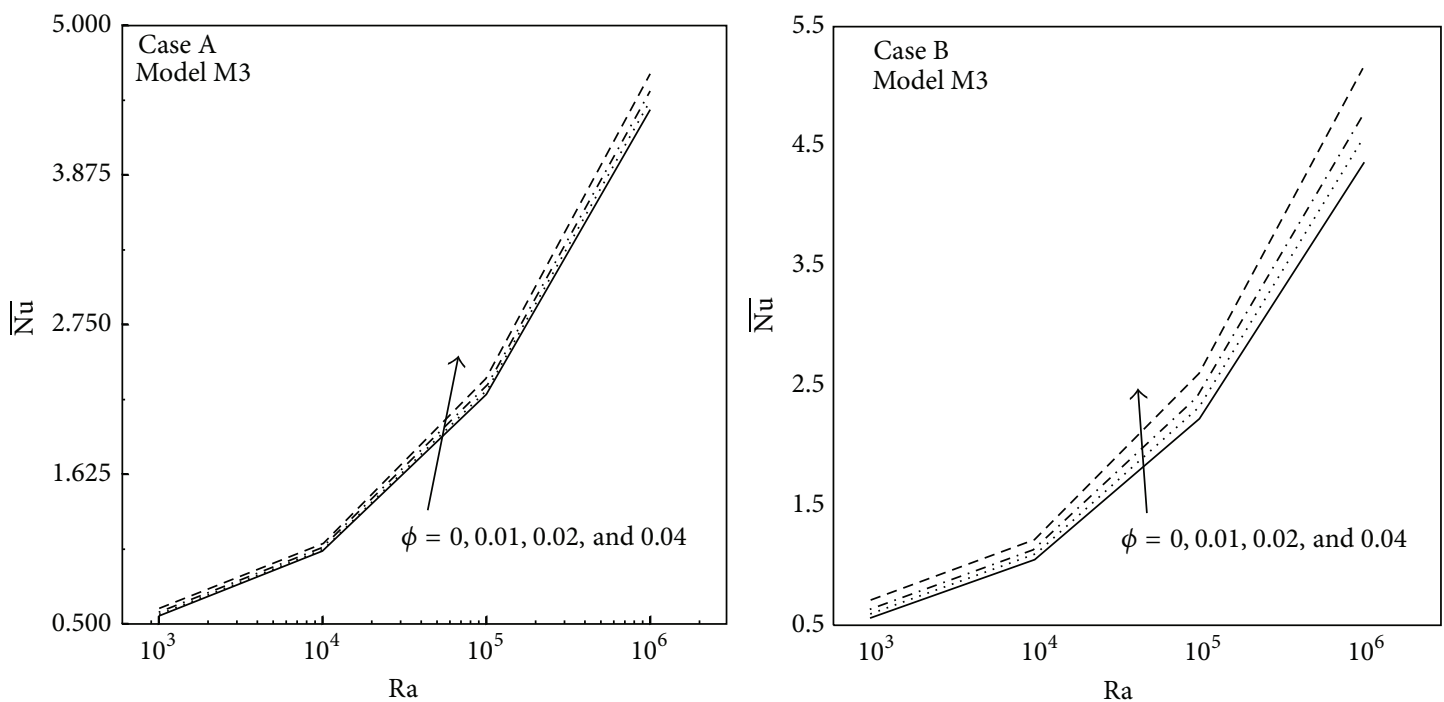

(c) Model M3

Figure 5: Continued. 

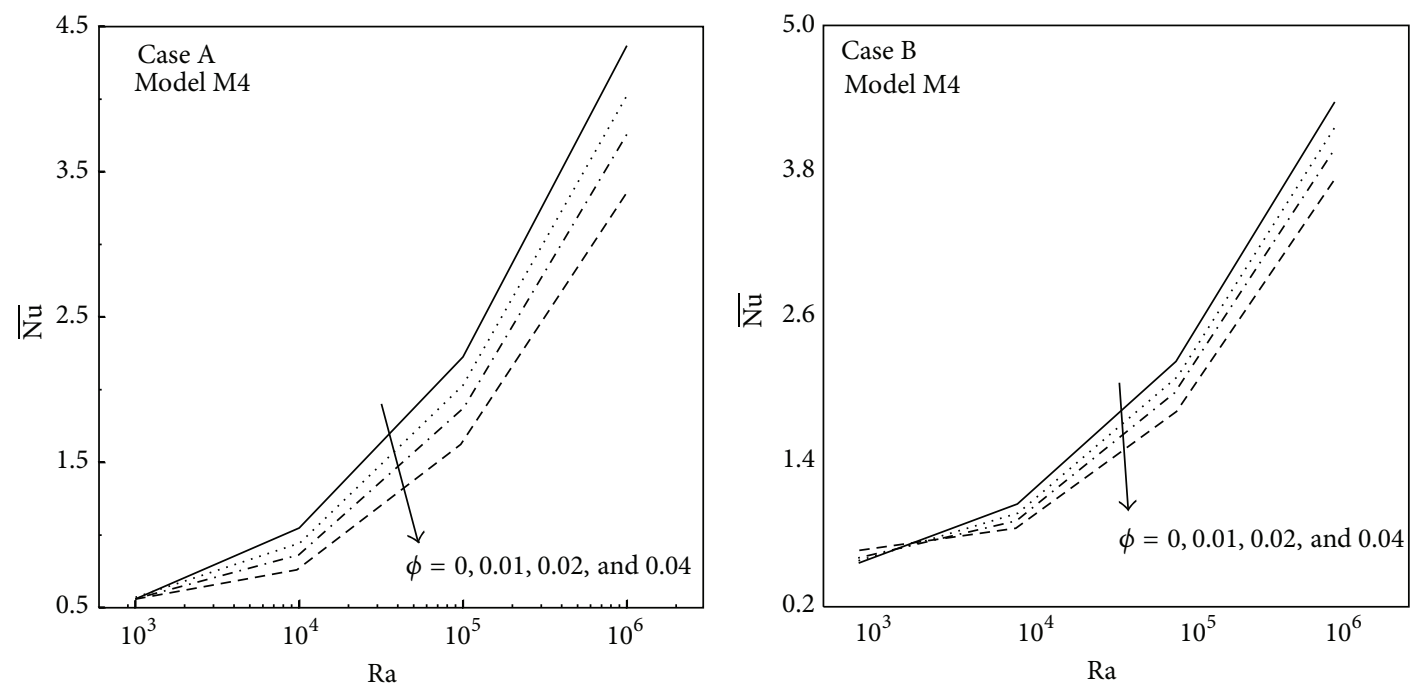

(d) Model M4

FiguRE 5: Average Nusselt number versus Rayleigh number for different models.

From these results, it is concluded that theoretical models always give enhancement on heat transfer rate with increasing volume concentration of nanoparticles for all values of Rayleigh number. However, the models based on experimental data did not give general results with increasing volume concentration of nanoparticles for all values of Rayleigh number. Some models based on experimental data give enhancement on heat transfer and heat transfer rate decreases on increasing the volume concentration of nanoparticles in some models based on experimental data. In the present study, Maiga et al.s correlation for viscosity provides enhancement on heat transfer with Pak and Cho's thermal conductivity model for all values of Rayleigh number. However, the same model does not make enhancement on heat transfer with Maxwell's thermal conductivity model for high values of Rayleigh number. It is also found that the heat transfer rate decreases on increasing volume concentration using Pak and Cho's correlation of viscosity for all cases of thermal conductivity models. Therefore, it is difficult to predict whether heat transfer rate increases or decreases on increasing volume concentration of nanoparticles by using models based on experimental data. Hence, a further experimental study is needed to clarify this trend such that heat transfer rate increases or decreases on increasing volume concentration of nanoparticles. The average heat transfer rate across the cavity is increased or decreased with respect to the base fluid depending on the models considered.

\section{Conclusions}

The effect of effective viscosity and thermal conductivity of nanofluid on natural convection in a square cavity with linearly varying hot wall is studied numerically. The following are concluded from the present study. Linearly varying hot wall gives lower average heat transfer rate than the case of isothermal wall and the difference increases on increasing the Rayleigh number. It is found that a small change is observed in temperature field between the two thermal conductivity models of nanofluids when increasing volume fraction of nanoparticles. When increasing the volume fraction of the nanofluid, heat transfer rate increases for Models M1 and M3. The heat transfer rate decreases for Model M4 on increasing the volume fraction of the nanoparticle. The difference among the effective dynamic viscosity models of nanofluid plays an important role here such that the average Nusselt number demonstrates an increasing or decreasing trend with concentration of nanoparticle. It is found that heat transfer rate increases on increasing the value of Rayleigh number for all models of viscosity and thermal conductivity of nanofluid. The heat transfer coefficient ratio for a fixed volume concentration of nanoparticle drops drastically at $\mathrm{Ra}=10^{4}$ in all models and increased above $\mathrm{Ra}=10^{4}$. The average heat transfer rate across the cavity is increased or decreased with respect to the base fluid depending on the models considered. Since it is difficult to predict whether heat transfer rate increases or decreases on increasing volume concentration of nanoparticles by using models based on experimental data, a further study is needed to clarify this trend.

\section{Nomenclature}

$c_{p}:$ Specific heat, $\mathrm{J} / \mathrm{kg} \mathrm{K}$

g: Acceleration due to gravity, $\mathrm{m} / \mathrm{s}^{2}$

$H$ : Height of the enclosure, $\mathrm{m}$

$k$ : Thermal conductivity, $\mathrm{W} / \mathrm{mK}$

$L$ : Length of the enclosure, $\mathrm{m}$

$\mathrm{Nu}$ : Local Nusselt number

$\overline{\mathrm{Nu}}$ : Average Nusselt number

Pr: Prandtl number, $\nu_{f} / \mu_{f}$

p: Pressure, $\mathrm{Pa}$ 

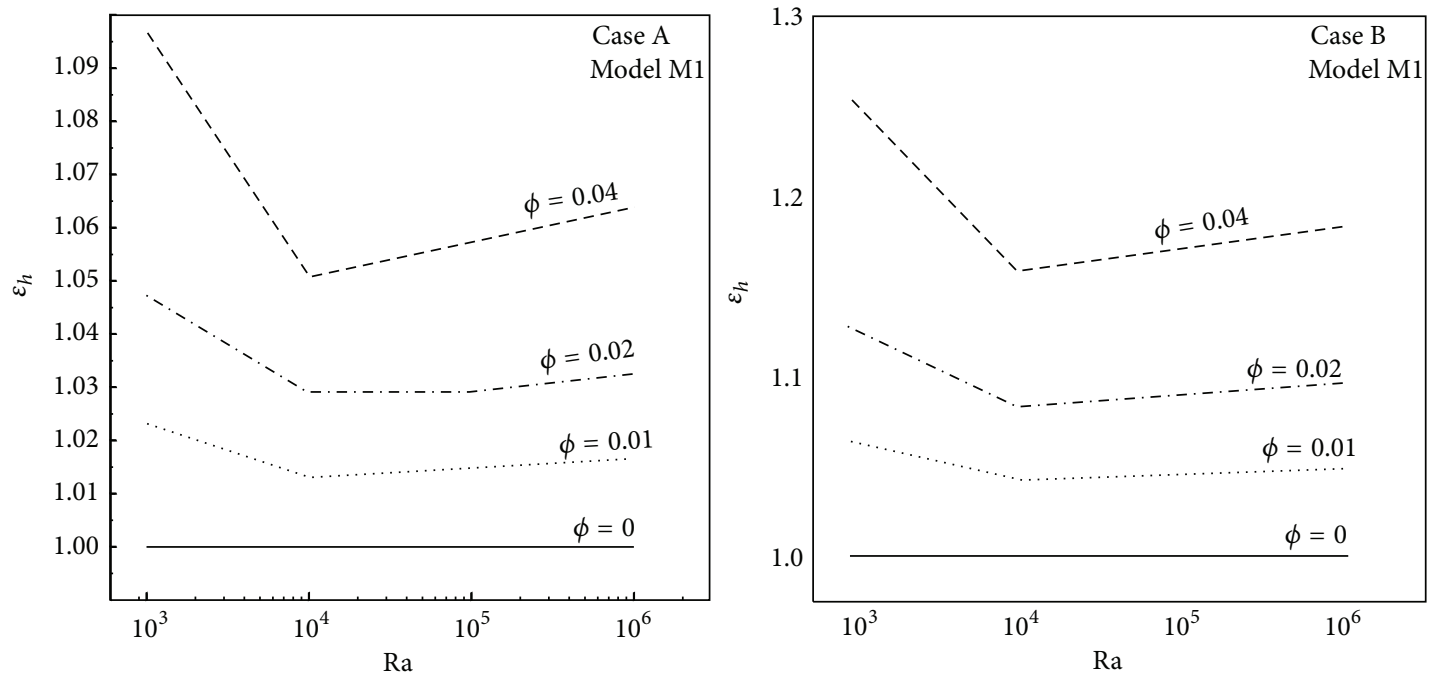

(a) Model M1
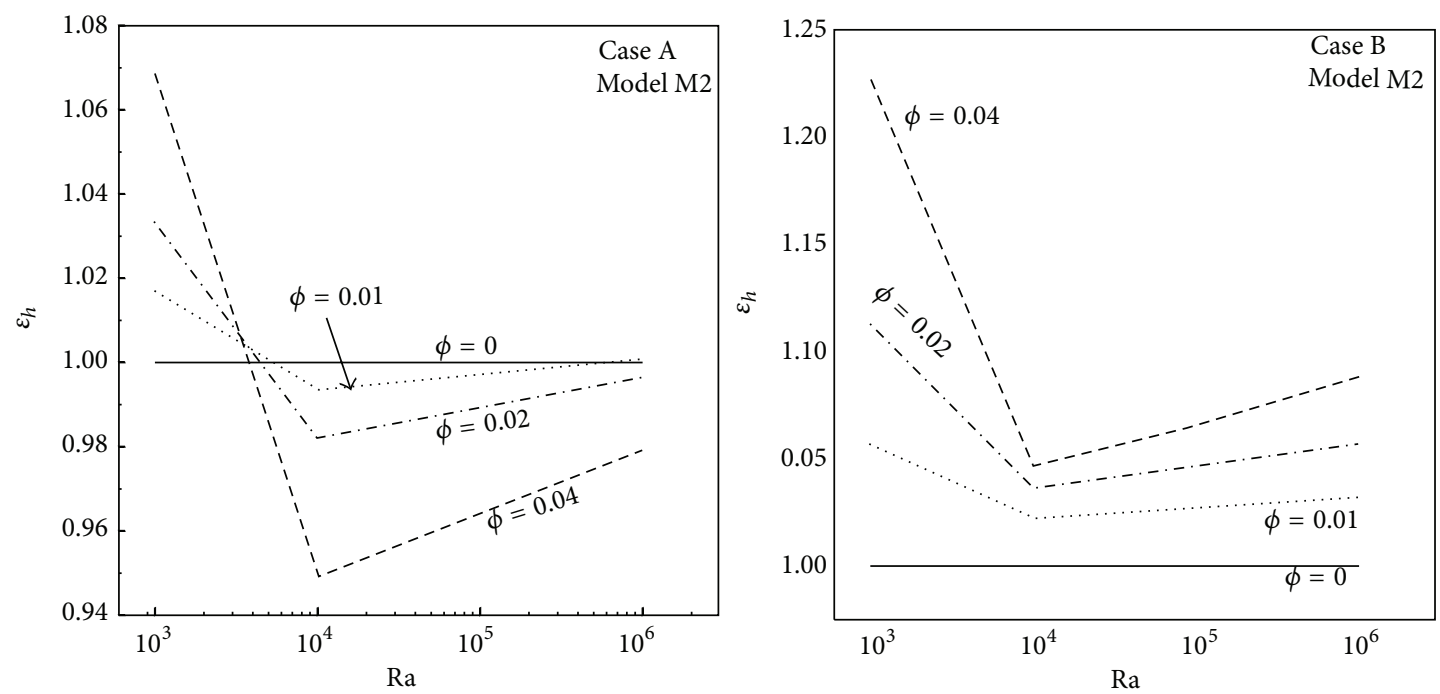

(b) Model M2
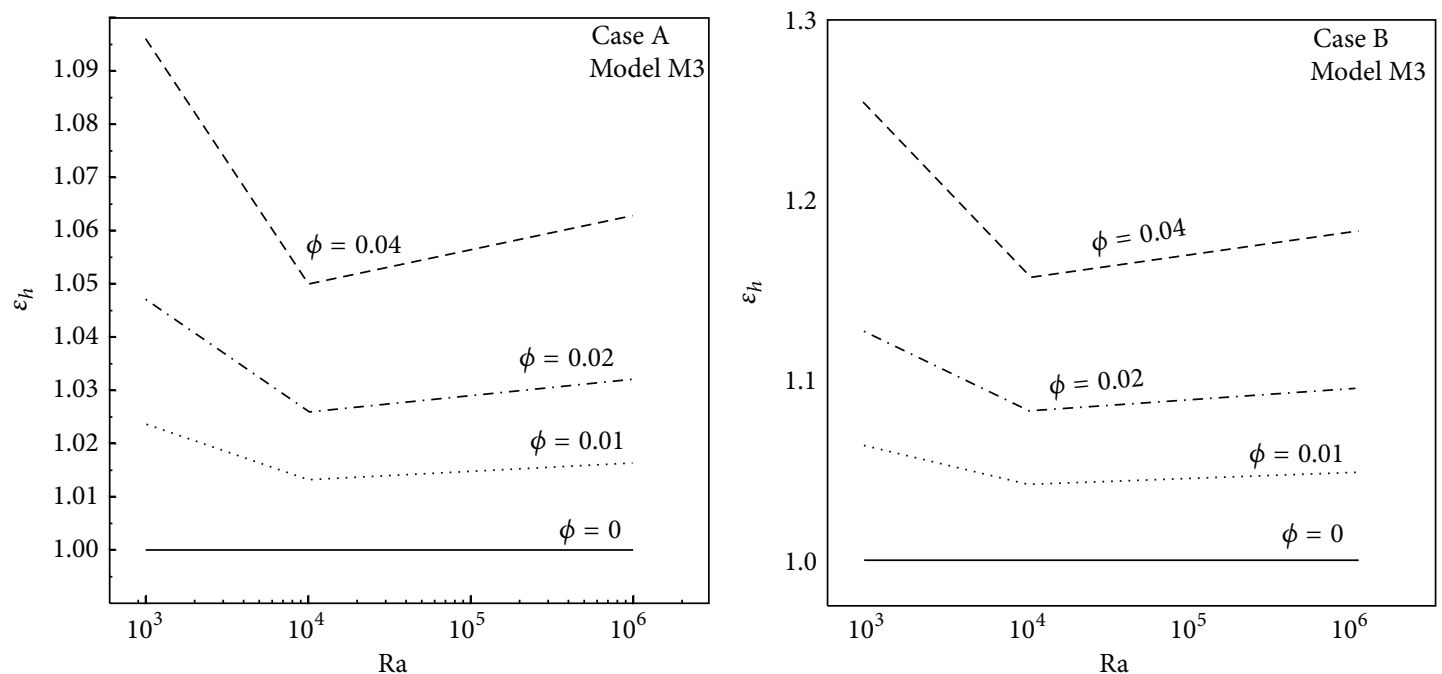

(c) Model M3

FIgURE 6: Continued. 

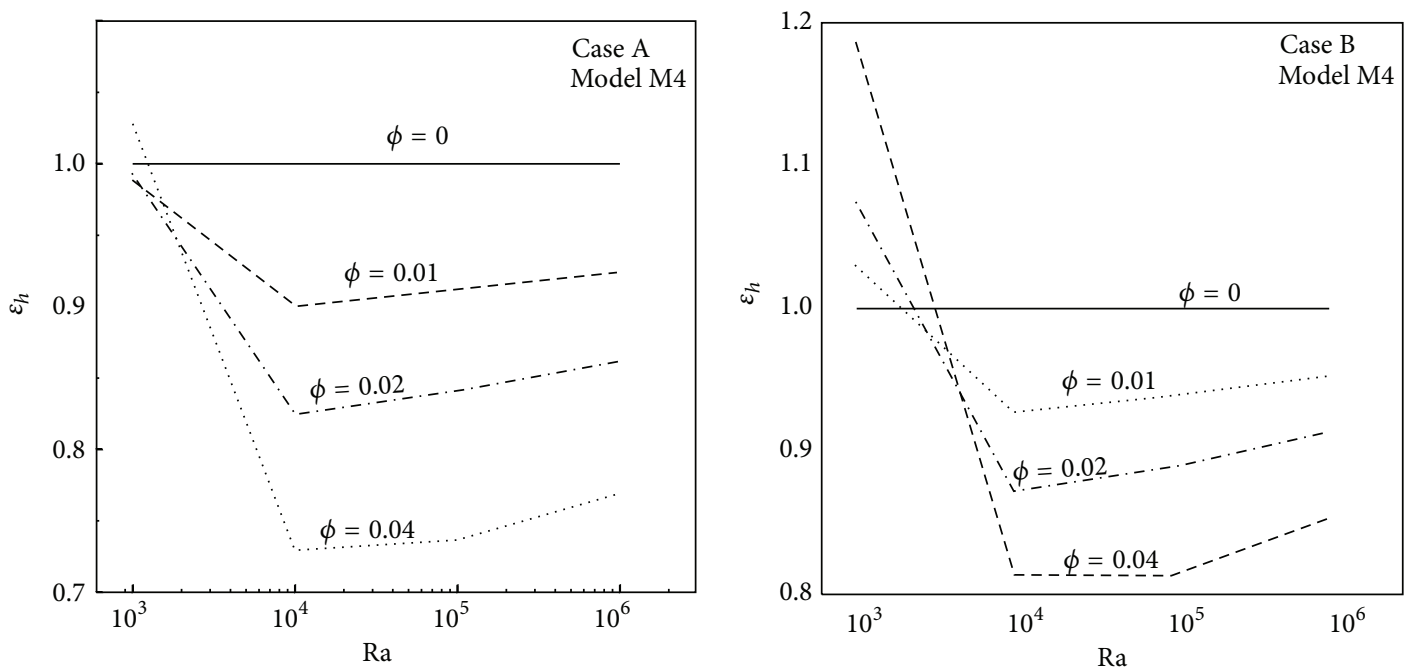

(d) Model M4

FIGURE 6: Heat transfer ratio versus Rayleigh number for different models.

Ra: Rayleigh number, $g \beta_{f}\left(\theta_{h}-\theta_{c}\right)^{b} L^{3} / \nu_{f} \alpha_{f}$

$T: \quad$ Dimensionless temperature, $\left(\theta-\theta_{c}\right) /\left(\theta_{h}-\theta_{c}\right)$

$t: \quad$ Time, $s$

$u, v:$ Velocity components, $\mathrm{m} / \mathrm{s}$

$U, V$ : Dimensionless velocity components.

\section{Greek Symbols}

$\alpha$ : Thermal diffusivity, $\mathrm{W} / \mathrm{mK}$

$\beta$ : Volumetric coefficient of thermal expansion, $1 / \mathrm{K}$

$\phi$ : Volume fraction of nanofluid

$\mu$ : Dynamic viscosity, $\mathrm{Pa} / \mathrm{s}$

$\nu$ : Kinematic viscosity, $\mu / \rho$

$\rho:$ Density, $\mathrm{kg} / \mathrm{m}^{3}$

$F_{o}$ : Dimensionless time

$\theta$ : Temperature, ${ }^{\circ} \mathrm{C}$.

\section{Subscripts}

c: Cold wall

$e$ : Effective

$h$ : Hot wall

$f$ : Base fluid

$n$ : Nanofluid

$p$ : Nanoparticle.

\section{Superscripts}

*: Property ratio.

\section{Conflict of Interests}

The authors declare that there is no conflict of interests regarding the publication of this paper.

\section{Acknowledgments}

The authors thankfully acknowledge the financial support from MOHE, UTM-Flagship Research Grant, Vote no. 01G40, under Research Manage Centre (RMC), Universiti Teknologi Malaysia, Johor Bahru, Malaysia, for completing this research work and the authors (M. Bhuvaneswari and Poobalan Ganesan) are grateful for the support from MOHE High Impact Research Grant (UM.C/HIR/MOHE/ENG/20), University of Malaya, Malaysia.

\section{References}

[1] J. Buongiorno, "Convective transport in nanofluids," Journal of Heat Transfer, vol. 128, no. 3, pp. 240-250, 2006.

[2] V. Trisaksri and S. Wongwises, "Critical review of heat transfer characteristics of nanofluids," Renewable and Sustainable Energy Reviews, vol. 11, no. 3, pp. 512-523, 2007.

[3] X.-Q. Wang and A. S. Mujumdar, "Heat transfer characteristics of nanofluids: a review," International Journal of Thermal Sciences, vol. 46, no. 1, pp. 1-19, 2007.

[4] Y. J. Hwang, Y. C. Ahn, H. S. Shin et al., "Investigation on characteristics of thermal conductivity enhancement of nanofluids," Current Applied Physics, vol. 6, no. 6, pp. 1068-1071, 2006.

[5] J. Philip, P. D. Shima, and B. Raj, "Nanofluid with tunable thermal properties," Applied Physics Letters, vol. 92, no. 4, Article ID 043108, 2008.

[6] G. Polidori, S. Fohanno, and C. T. Nguyen, "A note on heat transfer modelling of Newtonian nanofluids in laminar free convection," International Journal of Thermal Sciences, vol. 46, no. 8, pp. 739-744, 2007.

[7] K. Khanafer, K. Vafai, and M. Lightstone, "Buoyancy-driven heat transfer enhancement in a two-dimensional enclosure utilizing nanofluids," International Journal of Heat and Mass Transfer, vol. 46, no. 19, pp. 3639-3653, 2003. 
[8] K. S. Hwang, J.-H. Lee, and S. P. Jang, "Buoyancy-driven heat transfer of water-based $\mathrm{Al}_{2} \mathrm{O} 3$ nanofluids in a rectangular cavity," International Journal of Heat and Mass Transfer, vol. 50, no. 19-20, pp. 4003-4010, 2007.

[9] C. J. Ho, M. W. Chen, and Z. W. Li, "Numerical simulation of natural convection of nanofluid in a square enclosure: effects due to uncertainties of viscosity and thermal conductivity," International Journal of Heat and Mass Transfer, vol. 51, no. 1718, pp. 4506-4516, 2008.

[10] R.-Y. Jou and S.-C. Tzeng, "Numerical research of nature convective heat transfer enhancement filled with nanofluids in rectangular enclosures," International Communications in Heat and Mass Transfer, vol. 33, no. 6, pp. 727-736, 2006.

[11] A. K. Santra, S. Sen, and N. Chakraborty, "Study of heat transfer augmentation in a differentially heated square cavity using copper-water nanofluid," International Journal of Thermal Sciences, vol. 47, no. 9, pp. 1113-1122, 2008.

[12] S. Sivasankaran, T. Aasaithambi, and S. Rajan, "Natural convection of nanofluids in a cavity with linearly varying wall temperature," Maejo International Journal of Science and Technology, vol. 4, no. 3, pp. 468-482, 2010.

[13] W. Rashmi, A. F. Ismail, M. Khalid, and Y. Faridah, "CFD studies on natural convection heat transfer of $\mathrm{Al}_{2} \mathrm{O}_{3}$-water nanofluids," Heat and Mass Transfer, vol. 47, no. 10, pp. 1301-1310, 2011.

[14] S. Sivasankaran and K. L. Pan, "Natural convection of nanofluids in a cavity with nonuniform temperature distributions on side walls," Numerical Heat Transfer; Part A: Applications, vol. 65, no. 3, pp. 247-268, 2014.

[15] C. Cianfrini, M. Corcione, E. Habib, and A. Quintino, "Buoyancy-induced convection in $\mathrm{Al}_{2} \mathrm{O}_{3}$ /water nanofluids from an enclosed heater," European Journal of Mechanics B/Fluids, vol. 48, pp. 123-134, 2014.

[16] M. Bouhalleb and H. Abbassi, "Natural convection of nanofluids in enclosures with low aspect ratios," International Journal of Hydrogen Energy, vol. 39, pp. 15275-15286, 2014.

[17] S. Sivasankaran and C. J. Ho, "Buoyancy- and thermocapillaryinduced convection of cold water in an open enclosure with variable fluid properties," Numerical Heat Transfer, Part A: Applications, vol. 58, no. 6, pp. 457-474, 2010.

[18] S. Sivasankaran, M. Bhuvaneswari, Y. J. Kim, C. J. Ho, and K. L. Pan, "Numerical study on magneto-convection of cold water in an open cavity with variable fluid properties," International Journal of Heat and Fluid Flow, vol. 32, no. 5, pp. 932-942, 2011.

[19] H. C. Brinkman, "The viscosity of concentrated suspensions and solutions," The Journal of Chemical Physics, vol. 20, no. 4, p. $571,1952$.

[20] S. E. B. Maiga, C. T. Nguyen, N. Galanis, and G. Roy, "Heat transfer enhancement in forced convection laminar tube flow by using nanofluids," in Proceedings of the International Symposium on Advances in Computational Heat Transfer, Paper CHT040101, p. 24, 2004. 


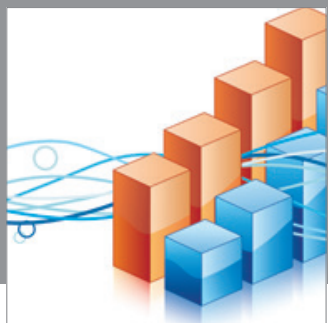

Advances in

Operations Research

mansans

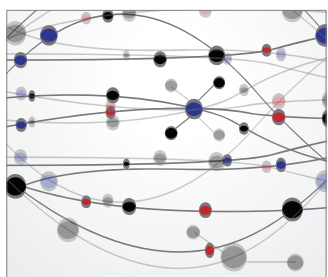

The Scientific World Journal
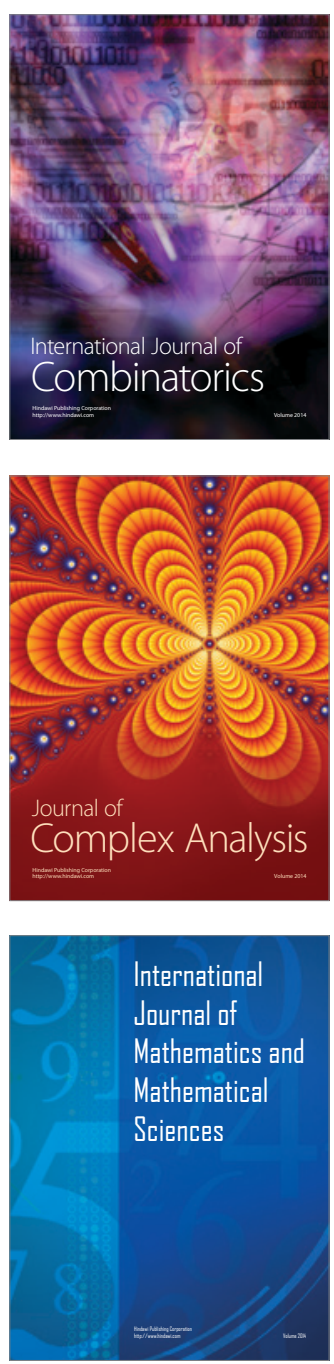
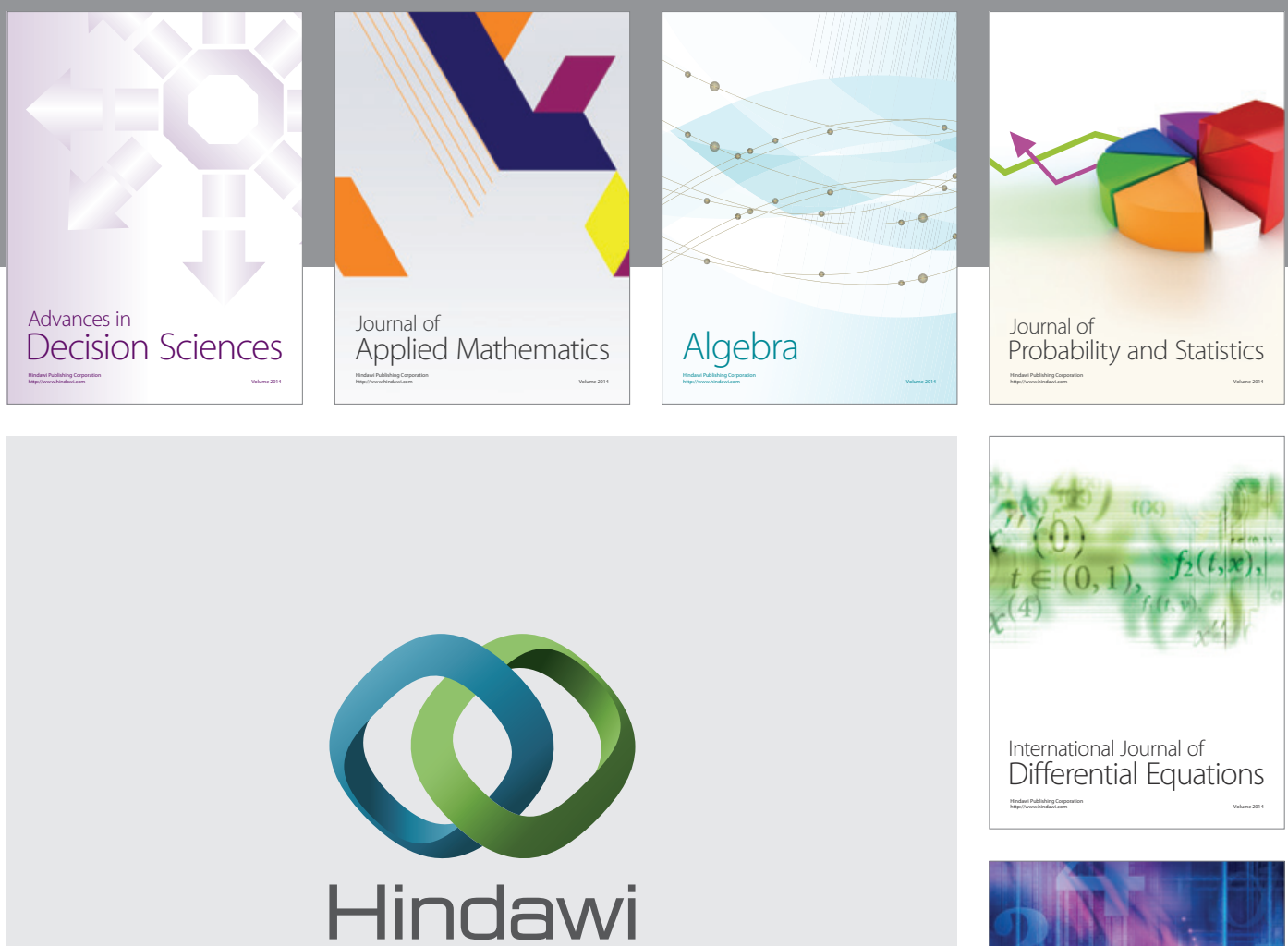

Submit your manuscripts at http://www.hindawi.com
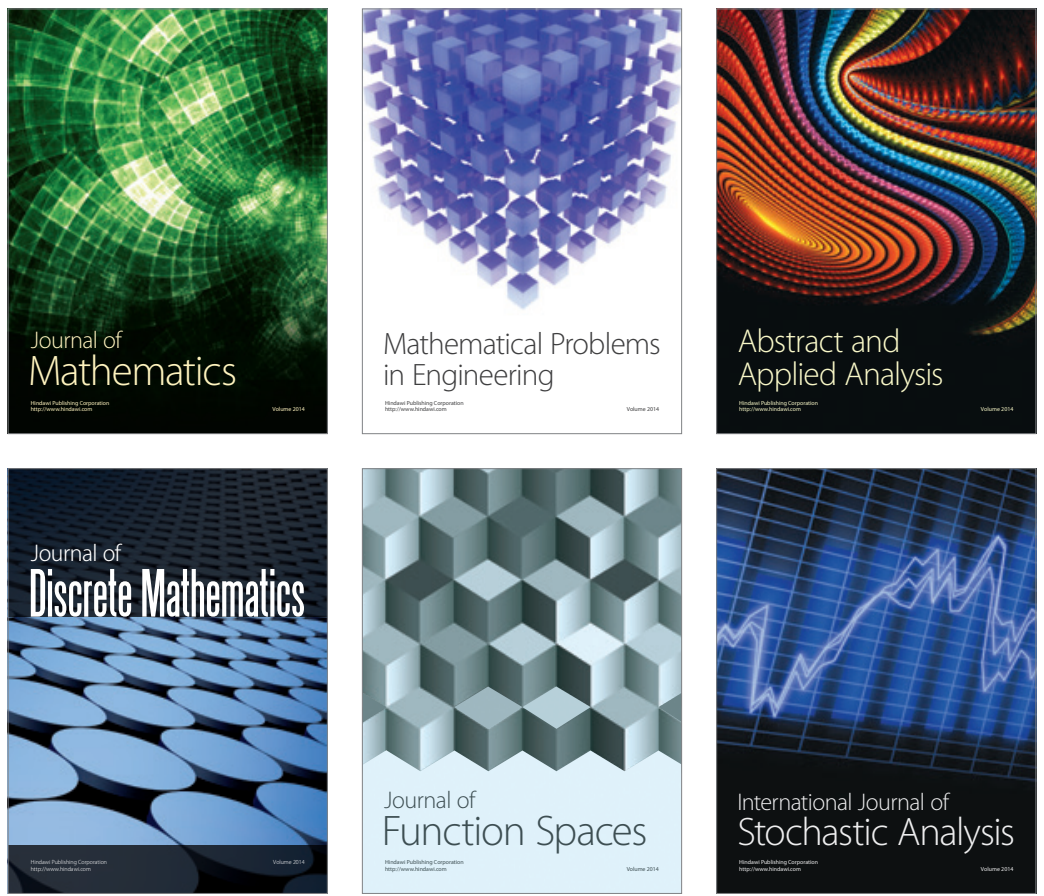

Journal of

Function Spaces

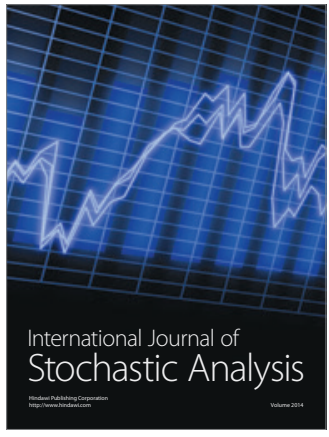

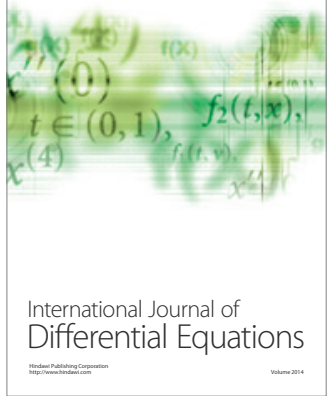
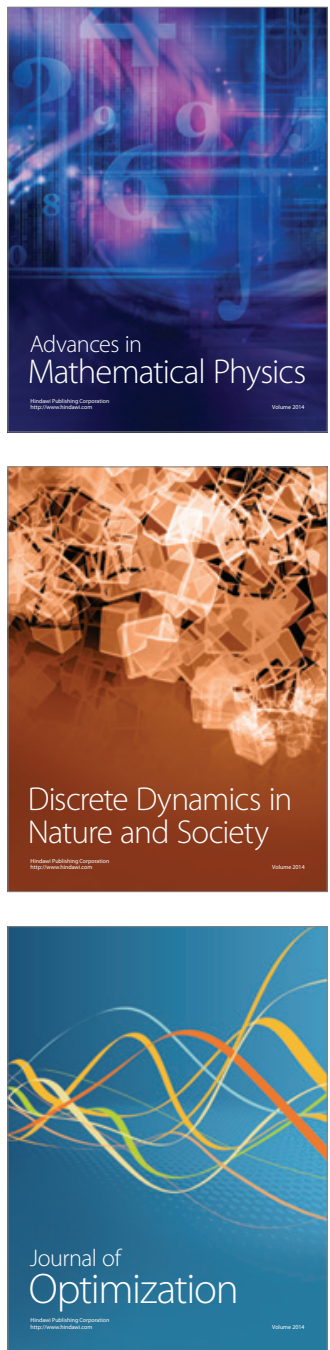